\title{
Cricothyrotomy training increases adherence to the ASA difficult airway algorithm in a simulated crisis: a randomized controlled trial
}

\section{La formation à la cricothyrotomie améliore l'observance à l'algorithme de gestion des voies respiratoires difficiles de l'ASA dans une crise simulée: essai randomisé contrôlé}

\author{
Kong Eric You-Ten, MD, PhD • M. Dylan Bould, MD • Zeev Friedman, MD • \\ Nicole Riem, MD • Devin Sydor, MD · Sylvain Boet, MD
}

Received: 21 May 2014/ Accepted: 17 December 2014/Published online: 30 December 2014

(C) Canadian Anesthesiologists' Society 2014

\begin{abstract}
Purpose Non-adherence to airway guidelines in a 'cannot intubate-cannot oxygenate' (CICO) crisis situation is associated with adverse patient outcomes. This study investigated the effects of hands-on training in cricothyrotomy on adherence to the American Society of Anesthesiologists difficult airway algorithm (ASA-DAA) during a simulated CICO scenario.

Methods A total of 21 postgraduate second-year anesthesia residents completed a pre-test teaching session during which they reviewed the ASA-DAA,

\footnotetext{
Author contributions Kong Eric You-Ten designed and conducted part of the study, analyzed the data, drafted the manuscript, and approved the final version for publication. M. Dylan Bould conducted part of the study, analyzed the data, and reviewed the manuscript. Zeev Friedman designed the study, analyzed the data, and reviewed the manuscript. Nicole Riem and Devin Sydor were raters for acquisition of data and reviewed the manuscript. Sylvain Boet analyzed the data and revised it critically for important intellectual content.
}

\section{K. E. You-Ten, MD, PhD ( $\varangle) \cdot$ Z. Friedman, MD}

Department of Anesthesia and Acute Pain Management, Mount Sinai Hospital, University of Toronto, 600 University Avenue, Rm 19-104, Toronto, ON M5G 1X5, Canada

e-mail: eyou-ten@mtsinai.on.ca

\section{D. Bould, MD}

Department of Anesthesia, Children's Hospital of Eastern

Ontario, Academy for Innovation in Medical Education,

University of Ottawa, Ottawa, ON, Canada

\section{N. Riem, MD}

Department of Anesthesia, Kantonsspital Baselland, University of Basel, Liestal, Switzerland became familiarized with the Melker cricothyrotomy kit, and watched a video on cricothyrotomy. Participants were randomized to either the intervention 'Trained' group $(n=10)$ (taught and practiced cricothyrotomy) or the control 'Non-Trained' group $(n=11)$ (no extra training). After two to three weeks, performances of the groups were assessed in a simulated CICO scenario. The primary outcome measure was major deviation from the ASA-DAA. Secondary outcome measures were (1) performance of the four categories of non-technical behaviours using the validated Anaesthetists' Non-Technical Skills scale (ANTS) and (2) time to perform specific tasks.

Results Significantly more non-trained than trained participants $(6 / 11$ vs $0 / 10, P=0.012)$ committed at least one major ASA-DAA deviation, including failure to insert an oral airway, failure to call for help, bypassing the laryngeal mask airway, and attempting fibreoptic intubation. ANTS scores for all four categories of behaviours, however, were similar between the groups.

D. Sydor, MD

Department of Anesthesia and Perioperative Medicine, Queen's University, Kingston General Hospital, Kingston, ON, Canada

S. Boet, MD

Department of Anesthesia, The Ottawa Hospital, Academy for Innovation in Medical Education, University of Ottawa, Ottawa, ON, Canada 
Trained participants called for help faster [26 (2) vs 63 (48) sec, $P=0.012]$ but delayed opening of the cricothyrotomy kit [130 (50) vs 74 (36) sec, $P=0.014]$.

Conclusion Hands-on training in cricothyrotomy resulted in fewer major ASA-DAA deviations in a simulated CICO scenario. Training in cricothyrotomy may play an important role in complying with the ASA-DAA in a CICO situation but does not appear to affect non-technical behaviours such as decision-making.

\section{Résumé}

Objectif La non-observance des lignes directrices concernant la gestion des voies respiratoires dans une situation de crise "Intubation impossible - oxygénation impossible»(CICO) est associée à des conséquences néfastes pour les patients. Cette étude a analysé les effets d'une formation pratique à la cricothyrotomie sur l'observance de l'algorithme de l'American Society of Anesthesiologists pour la gestion des voies respiratoires difficiles (ASA-DAA) au cours d'un scénario de CICO simulé.

Méthodes Un total de 21 résidents en anesthésie de deuxième année a suivi une session d'enseignement prétest au cours de laquelle ils ont étudié l'ASA-DAA, se sont familiarisés avec la trousse de cricothyrotomie de Melker et ont regardé une vidéo sur la cricothyrotomie. Les participants ont été randomisés en deux groupes: le groupe d'intervention "formé » $(n=10)$ (ayant appris et pratiqué la cricothyrotomie) et le groupe témoin "non formé » $(n=11)$ (sans formation supplémentaire). Après deux à trois semaines, la performance des groupes a été évaluée au moyen d'un scénario de CICO simulé. La mesure servant de critère d'évaluation principal était un écart majeur par rapport aux directives de l'ASA-DAA. Les mesures servant de critères d'évaluation secondaires étaient (1) la réalisation des quatre catégories de comportements non techniques utilisant l'échelle validée ANTS de compétences non techniques des anesthésiologistes et (2) le temps nécessaire à la réalisation de tâches spécifiques.

Résultats Un nombre significativement plus important de participants non formés que de participants formés (6/11 contre $0 / 10, P=0,012$ ) ont commis au moins un écart majeur à l'ASA-DAA, y compris l'échec d'insertion d'une voie respiratoire orale, l'absence d'appel à l'aide, la non-utilisation du masque laryngé d'intubation (MLI) et la tentative d'intubation avec fibre optique. Les scores de l'ANTS pour les quatre catégories de comportements ont cependant été semblables entre les groupes. Les participants formés ont plus rapidement appelé à l'aide (26 [2] contre 63 [48] sec, $P=0,012$ ) mais ont retardé l'ouverture de la trousse de cricothyrotomie (130 [50] contre 74 [36] sec, $P=0,014$ ).
Conclusion La formation pratique à la cricothyrotomie a entraîné moins d'écarts majeurs par rapport aux lignes directrices de l'ASA-DAA dans un scénario de CICO simulé. La formation à la cricothyrotomie peut jouer un rôle important dans l'observance de l'ASA-DAA dans une situation de CICO, mais ne semble pas affecter les comportements non techniques, tels que la prise de décision.

Airway complications are one of the leading causes of anesthesia-related morbidity and mortality. ${ }^{1,2}$ The first difficult airway management algorithm to improve clinical outcomes was introduced by the American Society of Anesthesiologists (ASA) in 1993. It is thought to have contributed to a significant decrease in airway-related adverse events during anesthesia induction. ${ }^{3}$ Airway management guidelines have been systematically developed to assist in making appropriate decisions. Although they are not intended to be standards or absolute requirements, they do provide a systematic approach to difficult airway management. ${ }^{3-5}$

Unanticipated difficult airways remain a challenge in anesthesia because their predictors are not $100 \%$ accurate..$^{1,2}$ An unanticipated difficult intubation can lead to a 'cannot intubate-cannot oxygenate' (CICO) airway crisis. When faced with this life-threatening crisis, an emergency cricothyrotomy is the final option. ${ }^{3-5}$ Cricothyrotomy is not a routine or common procedure, ${ }^{6}$ and a decline in the need for emergency surgical airways due to improvements in airway management has resulted in a lack of clinical experience and decreased exposure to this life-saving technique. ${ }^{7}$ Reluctance to perform cricothyrotomy and non-adherence to airway guidelines have been associated with hypoxic brain injury and death during clinical CICO situations. ${ }^{89}$ Although the choices of technique and devices have been clearly addressed, less attention has been focused on the underlying cause(s) of non-adherence to airway guidelines when managing a $\mathrm{CICO}$ crisis.

Adherence to airway management guidelines in airway emergencies involves prompt and appropriate decisive actions that can improve patient outcomes. ${ }^{10,11}$ Taking decisive action involves the cognitive process of decisionmaking. For anesthesia, decision-making generally falls into the category of 'human factors' or, more specifically, 'non-technical skills or behaviours. ${ }^{12}$ Good decisionmaking is one of the main non-technical behaviours required for crisis management. Although technical and non-technical attributes are usually taught and assessed separately, several studies have demonstrated that technical skills performance and non-technical behavioural performance are positively associated. ${ }^{13,14}$ 


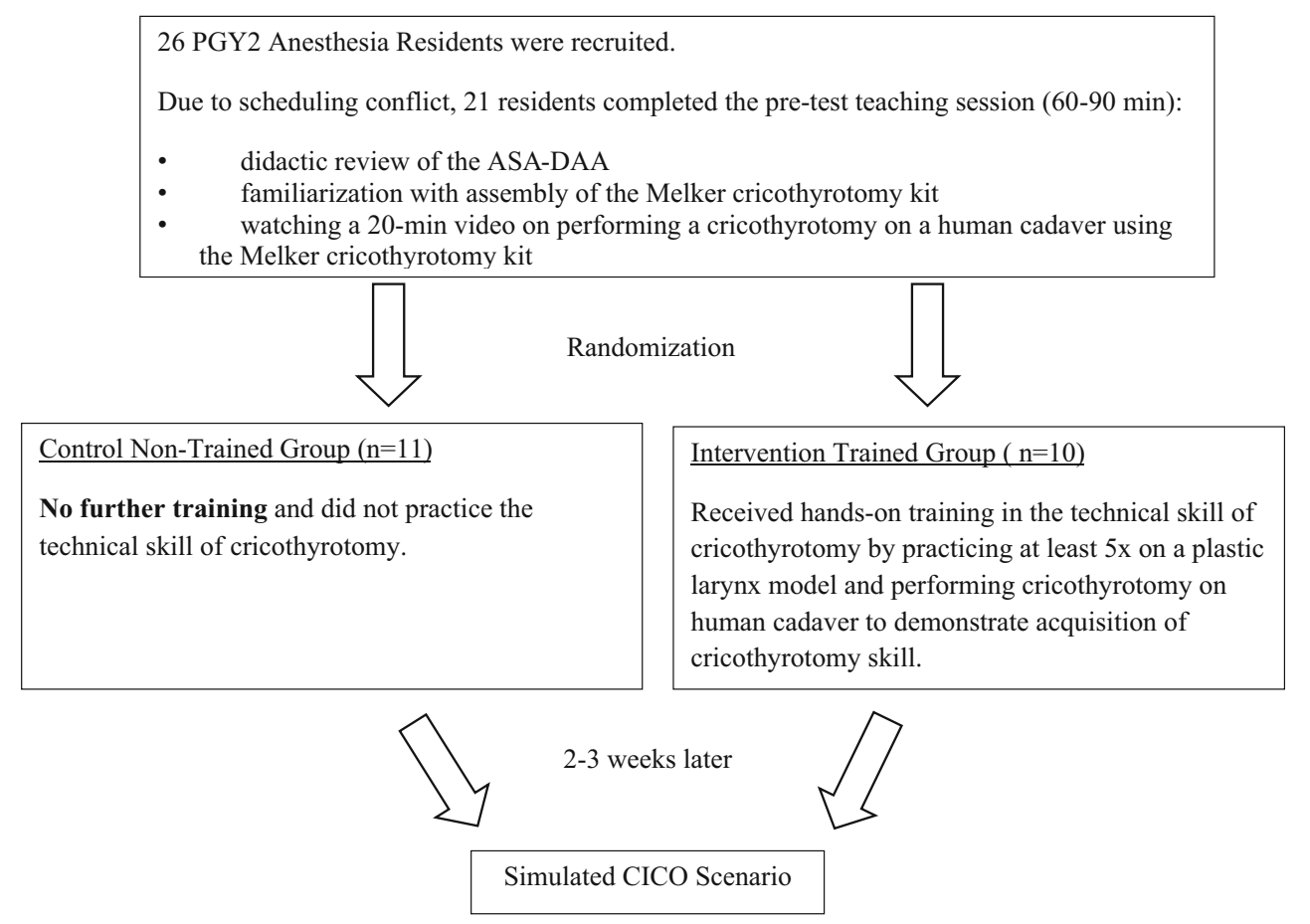

Figure Flow chart of study

Although these findings provide empirical evidence to suggest that these two sets of attributes are interrelated, those authors did not evaluate the nature of this relationship or the influence of technical skills training on non-technical behaviours. Understanding how these two skill sets interact could have broad implications for clinical performance in airway crisis management. One can assume that technical competence in cricothyrotomy may have an impact on adherence to the airway guidelines as a result of good decision-making in a difficult airway situation such as CICO. Indeed, the Fourth National Audit Project on airway complications in anesthesia emphasized the importance of cricothyrotomy technical skill and non-technical behaviours when managing CICO situations. ${ }^{15}$

The purpose of this randomized controlled study was to determine whether training in cricothyrotomy technical skill has an impact on adherence to the ASA difficult airway algorithm (ASA-DAA) and non-technical behaviours. We hypothesized that hands-on cricothyrotomy training would enhance adherence to the ASA-DAA as a result of improved decision-making.

\section{Methods}

\section{Participants}

The Institutional Research Ethics Board at Mount Sinai Hospital approved the study protocol in July 2007
(Toronto, ON, Canada). Participants were postgraduate year two (PGY2) anesthesia residents in the University of Toronto residency program. Participants who had performed a cricothyrotomy in a clinical or simulated setting within the past six months were excluded from the study. In all, 26 residents agreed to participate in the study and provided written informed consent. Because of scheduling conflicts, only 21 participants completed the study (Figure).

\section{Pre-test teaching session}

Participants were randomized into one of two groups using a computer algorithm: the 'Non-Trained' (control) group $(n=11)$ or the 'Trained' (intervention) group $(n=10)$. A staff anesthesiologist, blinded to group allocation, taught all participants in a 60 - to 90 -min pre-test teaching session that included a didactic review of the ASA-DAA, ${ }^{16}$ familiarization with the uncuffed $3.5 \mathrm{~mm}$ internal diameter Melker cricothyrotomy kit (Cook Medical Inc., IN, USA), and exposure to a 20-min instructional video (Cook Medical Inc., IN, USA) on performing cricothyrotomy on a human cadaver using the Melker kit. Teaching sessions were conducted in groups of one to three participants depending on the availability of the residents. The Melker kit was chosen because the residents were familiar with the Seldinger technique used during its placement. ${ }^{17}$ 
Hands-on training of cricothyrotomy skills

Following the pre-test teaching session, the Non-Trained group received no further training and did not practice the technical skills associated with cricothyrotomy performance. The Trained group received hands-on training by a second, unblinded staff anesthesiologist who was instructed to teach only the technical skills needed to perform cricothyrotomy. During hands-on training, the instructor did not teach or discuss the ASA-DAA, other airway technical skills, or airway management strategies. Participants were taught and practiced cricothyrotomy using the Melker kit on a low-fidelity plastic model, as described in our previous study. ${ }^{18}$ This model consists of a 10 -cm corrugated plastic tube with a slit opening covered with tape to imitate the cricothyroid membrane. The tube was covered with a silicone membrane that has the texture of skin and mimics the trachea. Participants practiced the procedure a minimum of five times on the model until they achieved plateau performance, as defined by Wong et al. ${ }^{19}$ Cricothyrotomy was then performed on a human cadaver to demonstrate their skill acquisition, which was confirmed by dissecting the cadaver's neck to identify correct placement of the airway device. ${ }^{18}$ The duration of the hands-on training session was $60 \mathrm{~min}$.

\section{Simulation scenarios}

Two to three weeks later, each participant completed a simulated CICO scenario on a high-fidelity Simman ${ }^{\circledR}$ mannequin (Laerdal Medical Canada Ltd, ON, Canada). The simulation scenarios took place in a mock operating room, where actors played the scripted roles of an operating room nurse and a respiratory therapist, respectively. Each performance was video-recorded.

The simulation room was equipped with basic airway devices. They included McIntosh laryngoscope blades sizes 3 and 4, a Miller laryngoscope blade, a gum elastic bougie, and sizes 3-5 laryngeal mask airways (LMAs). A video-laryngoscope (Glidescope ${ }^{\circledR}$ ) and/or the difficult airway cart were brought in upon request. The airway cart carried a fibreoptic bronchoscope and the Melker cricothyrotomy kit.

Prior to activating the scenario, each participant was oriented to the simulation room and the equipment. The participant acted the role of a senior anesthesia resident who was taking over a case from a staff anesthesiologist. Prior to induction of general anesthesia, the staff anesthesiologist was called to attend elsewhere, and the participant was instructed to proceed with the general anesthesia. The 'surgeon' was scrubbed and was imagined to be outside the operating room. A nurse actor was present at induction of anesthesia, and a respiration therapist actor
Table 1 Participant characteristics

\begin{tabular}{lll}
\hline Characteristics & $\begin{array}{l}\text { Non-Trained } \\
(n=11)\end{array}$ & $\begin{array}{l}\text { Trained } \\
(n=10)\end{array}$ \\
\hline *Scenario A: mScenario A & $5: 6$ & $4: 6$ \\
$\begin{array}{l}\text { No. of previous simulation } \\
\text { sessions }\end{array}$ & $1-2$ & $1-2$ \\
Male: female & $3: 8$ & $7: 3$ \\
\hline
\end{tabular}

*Ratio of number of participants in Scenario A: mScenario A. Mean (SD) duration of CICO situation was similar in Scenario A and modified (mScenario) A [197 (74) vs 209 (86) sec, $P=0.752$ ]

-Each participant in both groups had one to two previous sessions in simulation prior to the study

was available upon request. After completion of the scenario each participant was debriefed on his or her performance.

\section{Scenario A}

Five Non-Trained and four Trained residents in a first cohort of nine participants completed scenario A (Table 1). The participants administered standard general anesthesia for an elective laparoscopic cholecystectomy using propofol, fentanyl, and rocuronium to a simulated healthy patient with a Mallampati 2 airway. On the first attempt at laryngoscopic intubation with a McIntosh blade 3, the participant encountered an unanticipated 'cannot intubatecan oxygenate' situation caused by a grade IV view that had been simulated by inducing tongue swelling and pharyngeal blockage in the mannequin. Following adequate mask ventilation to maintain $97 \%$ oxygen saturation, a second intubation was attempted. Thirty seconds later, the oxygen saturation declined from $97 \%$ to reach a nadir of $70 \%$. Mask ventilation was inadequate during desaturation, initiating a CICO crisis. The scenario was terminated just prior to puncturing the mannequin's cricothyroid membrane (which would have been necessary), indicating the need for cricothyrotomy. As cricothyrotomy was not the technical skill being assessed in this scenarioand the Non-Trained residents had not practiced the technique-it was not performed.

\section{Modified scenario A}

We noted that participants involved in Scenario A (five Non-Trained and four Trained) bag-mask ventilated the mannequin for a prolonged period after the first failed intubation (i.e., during the "cannot intubate-can oxygenate" period). It delayed progression of the scenario to the second intubation attempt and subsequent CICO situation. To avoid this delay, Scenario A was modified to 
exclude the "cannot intubate-can oxygenate" situation (becoming 'mScenario A'). This change was acceptable because each participant's performance was rated only during management of the CICO crisis. The subsequent cohort of 12 participants who completed mScenario A involved six Non-Trained and six Trained residents (Table 1). The general anesthesia protocol and surgical scenario were the same as in Scenario A, except that the CICO situation was now encountered after the first failed laryngoscopic intubation event (caused by a grade IV view and inadequate mask ventilation), leading to severe hypoxia with $70 \%$ oxygen saturation. The conclusion of mScenario A was identical to that of Scenario A. The CICO crisis was identical in the two scenarios.

Data recording and analysis

Only the CICO crisis was analyzed in the videos. The CICO crisis was defined as the interval during which the oxygen saturation declined from $97 \%$ to $92 \%$ until completion of the scenario, just prior to performing the neck incision. Because the CICO crises in Scenario A and mScenario A were identical, the outcomes for each of the groups were pooled (Table 1).

The primary outcome measure was the number of participants who committed major deviations from the ASA-DAA. ${ }^{16}$ The deviations included (1) failure to insert an oral airway; (2) failure to call for help; (3) bypassing the LMA; and (4) attempted fibreoptic intubation. A secondary outcome measure was the performance rating of the four categories of non-technical behaviours using the previously validated Anaesthetists' Non-Technical Skills (ANTS) scale $^{12}$ (Appendix) by two independent raters blinded to group allocation. Each of the four ANTS categories-task management, teamwork, situation awareness, decisionmaking - was scored on a one to four scale (four being the highest and one the lowest). The total ANTS score was the sum of the scores for each behaviour category. The other secondary outcome measures were the time intervals between four specific procedural tasks: calling for help; inserting a LMA; opening the cricothyrotomy kit; preparing to puncture the cricothyroid membrane (i.e., 'cricothyrotomy').

\section{Statistical analyses}

We demonstrated in a previous study that there was at least a $50 \%$ improvement in performance following formal training in cricothyrotomy. ${ }^{18}$ In the present study, we assumed a $50 \%$ difference in the number of participants committing at least a major deviation from the ASA-DAA between the Non-Trained and Trained groups. We calculated that this difference would require 11 participants in each group (5\% alpha and $80 \%$ power). With an estimated attrition rate of $15 \%$, we recruited 13 participants per group. Primary outcome measures were analyzed using Fisher's exact test. Secondary outcome measures were analyzed using the Wilcoxon test. Participant characteristics were analyzed using the MannWhitney test for ordinal data and Fisher's exact test for nominal data. Inter-rater reliability between the two independent raters was evaluated using the intra-class correlation coefficient for the ANTS scores. Parametric data are presented as the mean (SD). A statistical difference of $P<0.05$ was considered to indicate significance in all analyses. Statistical analyses were performed using SAS System 9.2 (SAS Institute Inc., NC, USA).

\section{Results}

Demographic data for the two groups were not significantly different with respect to previous simulation sessions or experience with clinical or simulated CICO airway crises (Table 1). Significantly more participants in the NonTrained group than the Trained group committed at least one major deviation of the ASA-DAA: $54.5 \%$ (6/11) vs $0 \%$ (0/10), respectively; mean difference [MD] 54.5\%; $95 \%$ confidence intervals $[\mathrm{CI}] \quad 16.1$ to $78.7 ; \quad P=0.012$ (Table 2). Of the six Non-Trained participants who committed deviations, four committed one major deviation, one committed two, and one committed three. Of the four participants who committed one major deviation, one failed to insert an oral airway, one bypassed the LMA, and two attempted fibreoptic intubation during the period of severe hypoxia. One participant committed two major deviations: failing to insert an oral airway and bypassing the LMA. One participant committed three major deviations: failure to insert an oral airway, failure to call for help, and attempted fibreoptic intubation.

The secondary outcome measures of the time intervals between specific procedural tasks were also different between groups. The Non-Trained group had quicker mean (SD) times to call for help than the Trained group after oxygen desaturation to $92 \%$ (26 [27] vs 63 [48] sec, respectively; $\mathrm{MD}-37,95 \% \mathrm{CI}-74$ to $-0.4 ; P=0.012$ ) (Table 3). The Non-Trained group also took significantly longer mean (SD) times than the Trained group to request that a cricothyroidotomy kit be opened after failed LMA ventilation (130 [50] vs 74 [36] sec, respectively; MD 56, 95\% CI 14 to $98 ; P=0.014)$. The total ANTS and skill category scores for task management, situation awareness, decision-making, and teamwork were similar for the two groups (Table 4). The inter-rater reliability of ANTS 
Table 2 Participants committing major deviations from the ASA-DAA

\begin{tabular}{|c|c|c|c|c|}
\hline Major deviations & Non-Trained $\dagger n(\%)$ & Trained $\dagger n(\%)$ & $\% \mathrm{MD}(95 \% \mathrm{CI})$ & $* P$ value \\
\hline Failure to insert oral airway & $3 / 11(27.2)$ & $0 / 10(0)$ & $27.2(-5.5$ to 56.6$)$ & 0.21 \\
\hline Failure to call for help & $1 / 11(9.1)$ & $0 / 10(0)$ & $9.1(-19.6$ to 37.7$)$ & 1.0 \\
\hline Bypassed laryngeal mask & 2/11 (18.2) & $0 / 10(0)$ & $18.2(-12.5$ to 47.7$)$ & 0.48 \\
\hline Attempted fibreoptic intubation & $3 / 11(27.2)$ & $0 / 10(0)$ & $27.2(-5.5$ to 56.6$)$ & 0.21 \\
\hline One major deviation & $4 / 11(36.4)$ & $0 / 10(0)$ & $36.4(1.4$ to 64.6$)$ & 0.09 \\
\hline Two major deviations & $1 / 11(9.1)$ & $0 / 10(0)$ & $9.1(-19.6$ to 37.7$)$ & 1.0 \\
\hline Three major deviations & 1/11 (9.1) & $0 / 10(0)$ & $9.1(-19.6$ to 37.7$)$ & 1.0 \\
\hline At least one major deviation & $6 / 11(54.5)$ & $0 / 10(0)$ & 54.5 (16.1 to 78.7$)$ & 0.012 \\
\hline
\end{tabular}

$\dagger$ Values are number $(n)$ and percentage (\%) of participant(s) per group and \% mean difference (MD) with 95\% confidence intervals (CI)

$\uparrow$ The sum of the number of participants who committed one, two, and three major deviations

$* P<0.05$ is considered significant

ASA-DAA $=$ American Society of Anesthesiologists difficult airway algorithm

Table 3 Time intervals between procedural tasks in a CICO scenario

\begin{tabular}{|c|c|c|c|c|}
\hline Procedural tasks & Non-Trained $(n=11)$ & Trained $(n=10)$ & MD $(95 \% \mathrm{CI})$ & $* P$ value \\
\hline Oxygen desaturation ${ }^{*}$ to calling for help & 26 (27)\# & $63(48)$ & $-37(-74$ to -0.4$)$ & 0.012 \\
\hline Calling for help to LMA insertion & $64(44) \S$ & $49(43)$ & $15(-29$ to -49$)$ & 1.000 \\
\hline LMA insertion to opening Melker kit & $130(50) ¥$ & $74(36)$ & $56(14$ to 98$)$ & 0.014 \\
\hline Kit opening to cricothyrotomy ${ }^{\dagger}$ & $24(7)$ & $46(35)$ & $-22(-38$ to -6$)$ & 0.162 \\
\hline
\end{tabular}

Values are mean time (SD) in s, and mean difference (MD); 95\% confidence intervals (CI)

\$Oxygen desaturation from $97 \%$ to $92 \%$

\# Mean of this task was calculated based on ten participants due to one failure to call for help

$\S$ Mean of this task was calculated based on eight participants due to one failure to call for help and two bypassed LMA insertion

$¥$ Mean of this task was calculated based on nine participants due to two bypassed LMA insertion

$\lceil$ Cricothyrotomy was defined as just prior to puncturing the cricothyroid membrane of the mannequin

* $P<0.05$ is considered significant

$\mathrm{CICO}=$ 'cannot intubate-cannot oxygenate'; LMA = laryngeal mask airway

Table 4 Anaesthetists' Non-Technical Skills scores between Non-Trained and Trained groups

\begin{tabular}{lccl}
\hline${ }^{\#}$ ANTS category skills & Non-Trained $(n=11)$ & Trained $(n=10)$ & MD (95\% CI) \\
\hline Task management & $2.9(0.7)$ & $3.1(0.4)$ & $-0.2(-0.7$ to 0.3$)$ \\
Teamwork & $3.1(0.5)$ & $3.2(0.5)$ & $-0.1(-0.6$ to 0.4$)$ \\
Situation awareness & $2.9(0.8)$ & $2.9(0.7)$ & $0.0(-0.7$ to 0.7$)$ \\
Decision-making & $2.8(0.8)$ & $2.8(0.8)$ & $0.0(-0.7$ to 0.7$)$ \\
$\dagger$ Total ANTS & $11.7(2.8)$ & $12.1(2.4)$ & $-0.4(-2.8$ to 2$)$ \\
\hline
\end{tabular}

Values are mean score (SD) and mean difference (MD); 95\% confidence intervals (CI)

\#ANTS scores were rated on a scale of 1-4 (4, highest and 1, lowest)

$\dagger$ Total ANTS scores are the sum of the scores for each category skill

$* P<0.05$ is considered significant

ANTS $=$ Anaesthetists' Non-Technical Skills 
scoring was high, with an average intra-class correlation coefficient of 0.70 .

\section{Discussion}

We demonstrated that hands-on training in cricothyrotomy results in greater adherence to the ASA-DAA in a simulated CICO scenario. Despite prior pre-test review of the ASA-DAA, familiarization with the Melker cricothyrotomy kit, and watching a video on cricothyrotomy, only the participants who were not trained and did not practice (i.e., the Non-Trained group) the technical skill of cricothyrotomy committed major deviations of the ASA-DAA. Non-technical behaviours, however, were similar in the Trained and Non-Trained groups. These findings suggest that hands-on training in cricothyrotomy may play a role in adherence to airway guidelines in a CICO airway emergency, but it does not seem to affect nontechnical behaviours such as decision-making.

Our study showed that participants with extra hands-on training in cricothyrotomy did not commit major deviations of the ASA-DAA. This finding suggests that hands-on cricothyrotomy technical skill training can lead to increased adherence to the ASA-DAA. Our findings are in agreement with those of Kuduvalli et al., who demonstrated greater adherence to the Difficult Airway Society guidelines during a simulated CICO scenario after hands-on training in various airway technical skills. ${ }^{20}$ Hubert and colleagues also showed that simulation and airway technical skill training significantly improves anesthesia residents' compliance with difficult airway guidelines. ${ }^{21}$ On the other hand, technical skill uncertainty in internal medicine residents resulted in delays to indicated medical decisions and in some cases compromised patient outcomes. ${ }^{22}$ Our study not only reinforces the importance of hands-on training for improving technical skills, ${ }^{18-22}$ it demonstrates that it may enhance adherence to airway guidelines in a simulated CICO scenario.

Because of the extra training in cricothyrotomy, participants in the Trained group may have anticipated the CICO situation in the test scenario and mentally rehearsed its management. Mental rehearsal has been shown to be an effective form of learning because mentally simulating an action activates the same neural representation as the actual action. ${ }^{23}$ Mental rehearsal improves technical healthcare skills for performing various basic surgical tasks and simulated cricothyrotomy. ${ }^{24}$ Mental rehearsal of a CICO situation during hands-on practice by the Trained group could have led to their enhanced adherence to the ASA-DAA.

Although there is limited evidence to suggest a positive correlation between technical skill and non-technical behaviours, ${ }^{13,14}$ we did not find that cricothyrotomy technical skill had a direct effect on non-technical behaviours. That is, there were no differences in ANTS scores between groups for the four behavioural categories, including decision-making, which implies that hands-on training does not affect non-technical behaviours. A plausible explanation for this finding is that rating the four skill categories using ANTS may not have the granularity to capture specific non-technical behaviours. ${ }^{15}$ The four behavioural categories were subdivided into 15 element behaviours (Appendix). Rating the element behaviours of 'providing and maintaining standards' and 'balancing risks and selecting options' under 'decisionmaking' may have better captured differences in specific non-technical behaviours between the groups. A future study on whether rating the element behaviours captures the direct impact of technical skills on non-technical behaviours merits further research.

It is concerning that three residents in the Non-Trained group attempted fibreoptic intubation during significant hypoxia with an oxygen saturation of $70 \%$. This observation is consistent with a survey by Rosenstock et al., who reported that just under half of anesthesia residents would perform fibreoptic intubation in a CICO situation. ${ }^{25}$ This technique is not recommended in a CICO crisis because it puts patients at even greater risk, is time consuming, and requires high skill proficiency. ${ }^{26}$ Case reviews of patients who have died or suffered hypoxic brain injuries in clinical CICO situations have identified persistent intubation as one of the major determinants. ${ }^{8,9}$ These determinants are affected by several factors, including the external context (e.g., the environment and patient characteristics) and the internal context (e.g., the operator's own attributes). ${ }^{8}$ Our findings complement those of previous studies that showed that a lack of training in a crucial technical skill (i.e., cricothyrotomy) may also be a contributing factor.

Interestingly, although both groups sought help, the Non-Trained group called for help faster than the Trained group (Table 3). Seeking help early is recommended in all CICO algorithms and implies that the former group seemed more willing to call for help sooner. It is possible that the Non-Trained participants lacked the confidence to manage the CICO scenario. They had not received hands-on cricothyrotomy training and, as a result, sought help sooner. They also took almost twice as long to request opening of the Melker cricothyrotomy kit after failed LMA ventilation. Performing a cricothyrotomy without proper hands-on training can lead to failure and serious injuries that compromise patient safety. ${ }^{8}$ Alternatively, hands-on training may have made the Trained group overconfident and delayed their calls for help. Overconfidence is a source of medical errors that can adversely affect patient 
outcomes. ${ }^{27}$ Although hands-on training in cricothyrotomy has been shown to maintain skill competence, ${ }^{17-19}$ our findings suggest that it may also be detrimental to patient care by causing a delay in calling for help. It is therefore important to emphasize to junior anesthesia trainees during airway management training that calling for help early is appropriate.

Our decision to modify the scenario is a possible confounding factor that may have affected participants' performance. Participants in Scenario A might have anticipated the development of a CICO scenario and mentally rehearsed management strategies during the "can oxygenate" period. In contrast, participants in the modified scenario (mScenario A) had little time to prepare mentally because the "cannot intubate-can oxygenate" situation was removed from the scenario and the CICO situation occurred immediately after the first failed intubation attempt. This source of bias, however, did not appear to affect performance in the two scenarios. Although several participants in the Trained group (four in Scenario A and six in mScenario A; Table 1) were involved in each scenario, none deviated from the ASA-DAA. A major deviation was committed by at least one Non-Trained participant (five in Scenario A and six in mScenario A; Table 1) involved in each scenario.

Several limitations of this study warrant comment. First, the small sample size limits the generalizability of our results. We recruited only PGY2 residents into the study to minimize the effects of a higher residency training level on performance outcomes. Studies that have assessed crisis management performance of anesthesia trainees at different residency levels have shown that higher residency training is associated with faster correct decision-making and earlier resolution of the critical event. ${ }^{28,29}$ Second, the hands-on training in cricothyrotomy of the Trained group resulted in more time exposed to airway training, which may have improved adherence to the ASA-DAA. Extra time in education research remains a learning confounder and is difficult to eradicate. Also, learning over the course of the hands-on training could arguably affect performance when managing the CICO scenario. To minimize this potential bias, hands-on training in cricothyrotomy was focused strictly on procedural skills. There was no discussion of the ASA-DAA, other airway technical skills, or airway management strategies. A third limitation is that the hands-on training instructor could not be blinded to group allocation because only the participants randomized to the Trained group received hands-on training. The instructor was given strict instructions, however, to teach only the technical skills of cricothyrotomy using the Melker kit. A fourth limitation may relate to the artificial (i.e., plastic) characteristics of the mannequin. Tongue and pharyngeal swelling was induced in the mannequin to create a grade IV view, and it is possible that some participants in the Non-Trained group bypassed an oral airway and/or an LMA because of the reduced space in the mannequin's mouth. This is a possibility because we did not establish the reasons for these inactions during the debriefing. Finally, our difficult airway cart did not offer all the airway adjuncts listed in the ASA-DAA. A jet ventilator was not available, and this technique combined with needle cricothyrotomy may have been a preferred choice of residents in the Non-Trained group. Absence of this option may have caused these residents to alter their decisions and thus deviate from the ASA-DAA. We chose not to provide this option because of its inefficiency and high failure rate in patients and animal models. ${ }^{15,17}$

In summary, subjecting junior anesthesia residents to hands-on training in cricothyrotomy technical skills decreased deviations from the ASA-DAA airway algorithm in a simulated CICO scenario. It did not appear to affect non-technical behaviours, however, including decision making. Our findings suggest a possible role for hands-on training in cricothyrotomy to improve adherence to airway guidelines in a CICO airway emergency.

Acknowledgements We thank the following authors for their contributions: Dr. Michael Wylie, Ph.D. for the use of human cadavers; Dr. Devan Chandra, M.D., M.Ed. for scheduling the participants; Dr. Naveed Siddiqui, M.D. and Dr. Cristian Arzola, M.D. for each conducting one pre-test teaching session; Dr. Vern Naik, M.D., M.Ed. for the initial design of the study; and Mr. Roger Chow, B.Sc. for technical support in simulation sessions.

Funding This work was supported in part by research grants from the Ontario Physicians' Service Incorporation Foundation, The University of Toronto Innovation Fund in Education, and the Ontario Network of Excellence in Simulation for Clinical Teaching and Learning, Toronto, Ontario, Canada. SB was supported by the Department of Anaesthesiology of The Ottawa Hospital, University of Ottawa (Ottawa, Ontario, Canada).

Conflicts of interest None declared.

Appendix: Anaesthetists' Non-Technical Skills (ANTS) scale $^{12}$

\begin{tabular}{ll}
\hline Category & Element \\
\hline Task management & Planning and preparing \\
& Prioritizing \\
& Providing and maintaining standards \\
& Identifying and utilizing resources \\
\hline
\end{tabular}


Appendix continued

\begin{tabular}{|c|c|}
\hline Category & Element \\
\hline Teamworking & $\begin{array}{l}\text { Coordinating activities with team member } \\
\text { Exchanging information } \\
\text { Using authority and assertiveness } \\
\text { Assessing capabilities } \\
\text { Supporting others }\end{array}$ \\
\hline Situation awareness & $\begin{array}{l}\text { Gathering information } \\
\text { Recognizing and understanding } \\
\text { Anticipating }\end{array}$ \\
\hline Decision-making & $\begin{array}{l}\text { Identifying options } \\
\text { Balancing risks and selecting options } \\
\text { Re-evaluating }\end{array}$ \\
\hline
\end{tabular}

Rating Label Description

$\overline{4-\text { Good } \quad \text { Performance was of a consistently high standard, }}$ enhancing patient safety; it could be used as a positive example for others.

3-Acceptable Performance was of a satisfactory standard but could be improved.

2-Marginal Performance indicated cause for concern; considerable improvement is needed.

1-Poor Performance endangered or potentially endangered patient safety; serious remediation is required.

\section{References}

1. Cheney FW, Posner KL, Lee LA, Caplan RA, Domino KB. Trends in anesthesia-related death and brain damage: A closed claims analysis. Anesthesiology 2006; 105: 1081-6.

2. Cook TM, Bland L, Mihai R, Scott S. Litigation related to anaesthesia: an analysis of claims against the NHS in England 1995-2007. Anaesthesia 2009; 64: 706-18.

3. Caplan RA, Benumof JL, Berry FA, et al. American Society of Anesthesiologists Task Force on Management of the Difficult Airway: Practice guidelines for management of the difficult airway: A report by the American Society of Anesthesiologists Task Force on Management of the Difficult Airway. Anesthesiology 1993; 78: 597-602.

4. Henderson JJ, Popat MT, Latto IP, Pearce AC, Difficult Airway Society.. Difficult Airway Society guidelines for management of the unanticipated difficult intubation. Anaesthesia 2004; 59: 675-94.

5. Crosby ET, Cooper RM, Douglas MJ, et al. The unanticipated difficult airway with recommendations for management. Can $\mathbf{J}$ Anaesth 1998; 45: 757-76.

6. Wong DT, Lai K, Chung FF, Ho RY. Cannot intubate-cannot ventilate and difficult intubation strategies: results of a Canadian national survey. Anesth Analg 2005; 100: 1439-46.

7. Chang RS, Hamilton RJ, Carter WA. Declining rate of cricothyrotomy in trauma patients with an emergency medicine residency: implications for skills training. Acad Emerg Med 1998; 5: 247-51.

8. Greenland KB, Acott C, Segal R, Goulding G, Riley RH, Merry $A F$. Emergency surgical airway in life-threatening acute airway

emergencies-why are we so reluctant to do it? Anaesth Intensive Care 2011; 39: 578-84.

9. Harmer M, Bromiley M (2014) Independent Review on the Care Given to Mrs Elaine Bromiley on 29 March 2005. Available from URL : www.chfg.org/resources/07_qrt04/Anonymous_Report_ Verdict_and_Corrected_Timeline_Oct_07.pdf (accessed November 2014).

10. Combes $X$, Le Roux B, Suen P, et al. Unanticipated difficult airway in anesthetized patients: prospective validation of a management algorithm. Anesthesiology 2004; 100: 1146-50.

11. Heidegger T, Gerig HJ, Ulrich B, Kreienbuhl G. Validation of a simple algorithm for tracheal intubation: daily practice is the key to success in emergencies-an analysis of 13,248 intubations. Anesth Analg 2001; 92: 517-22.

12. Fletcher $G$, Flin $R$, McGeorge P, Glavin R, Maran $N$, Patey $R$. Anaesthetists' Non-Technical skill (ANTS): evaluation of a behavioural marker system. Br J Anaesth 2003; 90: 580-8.

13. Riem N, Boet $S$, Bould MD, Tavares W, Naik VN. Do technical skills correlate with non-technical skills in crisis resource management: a simulation study. Br J Anaesth 2012; 109: 723-8.

14. Gaba DM, Howard SK, Flanagan B, Smith BE, Fish KJ, Botney $R$. Assessment of clinical performance during simulated crises using both technical and behavioral ratings. Anesthesiology 1998; 89: 8-18.

15. Cook TM, Woodall N, Frerk C, Fourth National Audit Project. Major complications of airway management in the UK: results of the Fourth National Audit Project of the Royal College of Anaesthetists and the Difficult Airway Society. Part 1: anesthesia. Br J Anaesth 2011; 106: 617-31.

16. Caplan RA, Benumof JL, Berry FA, et al. American Society of Anesthesiologists Task Force on Management of the Difficult Airway. Practice guidelines for management of the difficult airway: an updated report by the American Society of Anesthesiologists Task Force on Management of the Difficult Airway. Anesthesiology 2003; 98: 1269-77.

17. Murphy C, Rooney SJ, Maharaj CH, Laffey JG, Harte BH. Comparison of three cuffed emergency percutaneous cricothyroidotomy devices to conventional surgical cricothyroidotomy in a porcine model. Br J Anaesth 2011; 106: 57-64.

18. Friedman Z, You-Ten KE, Bould MD, Naik V. Teaching lifesaving procedures: the impact of model fidelity on acquisition and transfer of cricothyrotomy skills to performance on cadavers. Anesth Analg 2008; 107: 1663-9.

19. Wong DT, Prabhu AJ, Coloma M, Imasogie N, Chung FF. What is the minimum training required for successful cricothyroidotomy?: a study in mannequins. Anesthesiology 2003; 98: 349-53.

20. Kuduvalli $P M$, Jervis A, Tighe $S Q$, Robin NM. Unanticipated difficult airway management in anaesthetised patients: a prospective study of the effect of mannequin training on management strategies and skill retention. Anaesthesia 2008; 63: 364-9.

21. Hubert V, Duwat A, Deransy R, Mahjoub $Y$, Dupont $H$. Effect of simulation training on compliance with difficult airway management algorithms, technical ability, and skills retention for emergency cricothyrotomy. Anesthesiology 2014; 120 : 999-1008.

22. Farnan JM, Johnson JK, Meltzer DO, Humphrey HJ, Arora VM. Resident uncertainty in clinical decision-making and impact on patient care: a qualitative study. Qual Saf Health Care 2008; 17: $122-6$.

23. Immenroth $M$, Burger $T$, Brenner $J$, Nagelschmidt $M$, Eberspacher H, Troidl H. Mental training in surgical education: a randomized controlled trial. Ann Surg 2007; 245: 385-91.

24. Arora $S$, Aggarwal $R$, Sirimanna $P$, et al. Mental practice enhances surgical technical skills: a randomized controlled study. Ann Surg. 2011; 253: 265-70. 
25. Rosenstock C, Ostergaard D, Kristensen MS, Lippert A, Ruhnau B, Rasmussen $L S$. Residents lack knowledge and practical skills in handling the difficult airway. Acta Anaesthesiol Scand 2004; 48: 1014-8.

26. Naik VN, Matsumoto ED, Houston PL, et al. Fiberoptic orotracheal intubation on anesthetized patients: do manipulation skills learned on a simple model transfer into the operating room? Anesthesiology 2001; 95: 343-8.
27. Berner ES, Graber ML. Overconfidence as a cause of diagnostic error in medicine. Am J Med 2008; 121(5 Suppl): S2-23.

28. Gaba DM, DeAnda A. The response of anesthesia trainees to simulated critical incidents. Anesth Analg 1989; 68: 444-51.

29. Byrne AJ, Jones JG. Responses to simulated anaesthetic emergencies by anaesthetists with different durations of clinical experience. Br J Anaesth 1997; 78: 553-6. 